Musculoskeletal disease

\title{
Degenerative musculoskeletal disease
}

\section{O Ethgen, J-Y Reginster}

\section{Is the demographic transition impacting on the perception of degenerative musculoskeletal disease?}

\section{AGING PROCESS}

The world is witnessing an unprecedented, irremediable, and longlasting aging process. ${ }^{12}$ Table 1 provides population decennial growth rates by 10 year age groups and shows marked differences across age groups. Figures 1 and 2 display the projected population distribution by 10 year age group. The graphs evidence quite well the "baby boomers" wave that is going to extend continuously the numbers of people over the age of 60 years.

Western Europe should see the numbers of its inhabitants aged below 50 decrease dramatically, while those above 60 should sharply increase. The number of Europeans older than 60 is projected to rise from 84570 thousands (21.8\% of Europeans) at present to 107592 thousands $(32.8 \%)$ in 2050. The increase is even more pronounced for the old-old $(80+)$ with the highest growth rate $(124.4 \%)$. Those aged $80+$ would rise impressively from 14610 thousands $(3.8 \%)$ in 2000 up to 38394 thousands $(10.7 \%)$ in 2045 and then stabilise. In North America, all age groups should increase in number until 2050, but growth rates are notably higher for those aged 60-69 (112.7\%), $70-79(104.3 \%)$ and, particularly, 80+ (234.3\%). Whereas 50876 thousands
(16.2\% of northern Americans) people were aged 60 in 2000, the number would be 118974 thousands (27.2\%) in 2050. Even faster than in Europe, those aged 80 and above would dramatically increase from 10094 thousands $(3.2 \%)$ in 2000 up to 33743 thousands $(7.7 \%)$ in 2050 .

\section{"The outstanding achievement of a longer life span is now one of the greater challenges for the current century"}

Aging represents a major societal progress characterising the continuous and remarkable expansion of life span over the past century. This outstanding attainment is now one of the greater challenges for the current century-that is, ensuring the quality of life of an unparalleled wide number of elderly people. ${ }^{3}$ As these latter have been the agents of that achievement, they must also be its beneficiaries.

\section{HEALTH AND QUALITY OF LIFE IN THE ELDERLY}

Health is the core of this challenge of quality of life in later years. Modern societies should be willing to afford the elderly a blooming health to ensure that they have every opportunity to remain active and productive. In modern societies, most communicable diseases are nowadays controlled or eradicated. Apart from changes in medical technology and individual factors, future healthcare management and costs will result from an increase in the prevalence of age related chronic and disabling conditions such as arthritis, which belongs to the most prevalent age related chronic conditions $s^{4-6}$ and which has been consistently found to be a leading cause of disability through wide population health survey. ${ }^{7-9}$ The large projected growth of the population aged above 60 suggests a sharp increase in the prevalence of arthritis for at least the four forthcomings decades.

Concern surrounding future arthritis prevalence is intensified when looking at the demographic dynamic. Global aging means that the increase in the number of elderly people occurs concomitantly with relatively minor changes (even decreases in Europe) in the size of the younger population. Dependency ratios (number of 60+/ number of 20-59) are expected to rise dramatically between 2000 and 2045, from 0.39 to 0.81 in Western Europe and from 0.29 to 0.55 in Northern America. The smaller proportion of people of working age will have major social implications for the supply of care and support to the even greater number of disabled people. ${ }^{1011}$ Typically, formal care for the disabled elderly is often substantially complemented by informal care and assistance provided by the family such as children. ${ }^{12}{ }^{13}$ With global aging, those supporting their elders would tend to be aged themselves (that is, over 60 years old) and so, they would be likely to develop arthritis and disabilities as well. Moreover, arthritis has been reported as an important cause of days lost from work. ${ }^{14-16}$ If we look at the

Table 1 Population decennial growth rates by age groups from 2000 to 2050 (\%)

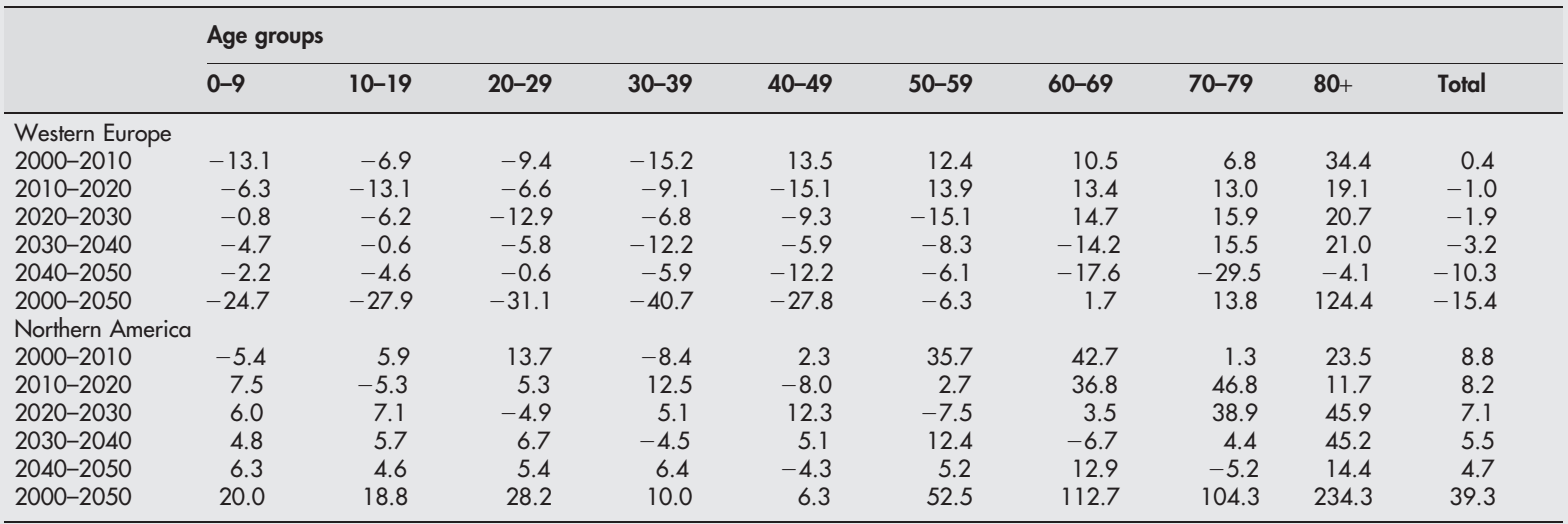

Source: Population Division of the Department of Economic and Social Affairs of the United Nations. ${ }^{2}$ Western Europe: Euro zone countries, United Kingdom, Sweden, Denmark, Norway and Switzerland; Northern America: USA and Canada. 


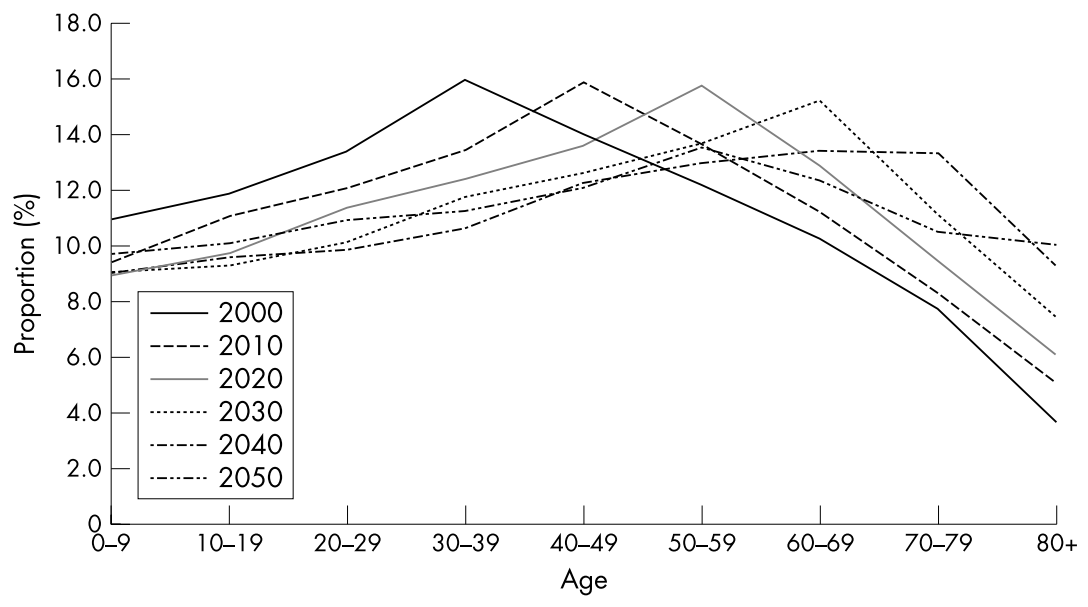

Figure 1 Population distribution by 10 year age group in Western Europe from 2000 to $2050 .^{2}$

working segment of the population, aging suggests that the size of the older working population (that is 50-60 years) has increased as well. Societies would be faced with an increasing part of their labour force affected by arthritis.

\section{"Global aging will mean that those supporting their elders will be old and, possibly arthritic, themselves"}

The socioeconomic burden attributable to arthritis is tremendous. Patients report significant impairment in their ability to perform activities of daily living and in their quality of life. ${ }^{17} 18$ The psychosocial dimension is also altered, with symptoms of depression having been noticed. ${ }^{19} 20$ As a consequence, arthritis results in towering healthcare costs. ${ }^{21} 22$ Non-medical costs are substantial as well. ${ }^{14-16}$ A thorough and recent review from national studies indicates that the economic costs of arthritis represent $1.5-2.5 \%$ of the gross national product (GNP), and total healthcare expenditure among those reporting arthritis approaches 3\% of the GNP. ${ }^{23}$

\section{ARTHRITIS: A NEGLECTED HEALTH PRIORITY}

However, the importance of the burden of arthritis on society remains underappreciated. Arthritis is too often viewed as a normal and irremediable part of the aging process. The "legitimacy" of arthritis seems firmly rooted in general opinion. Numerous patients believe that nothing, or very little, can be done against arthritis. ${ }^{24} 25$ Arthritis, and musculoskeletal conditions in general, remain low in national healthcare and research priorities. ${ }^{26}$ In the United States, a study investigating the relationship between funding by the National Institute of Health and the burden of diseases included neither arthritis nor any other musculoskeletal

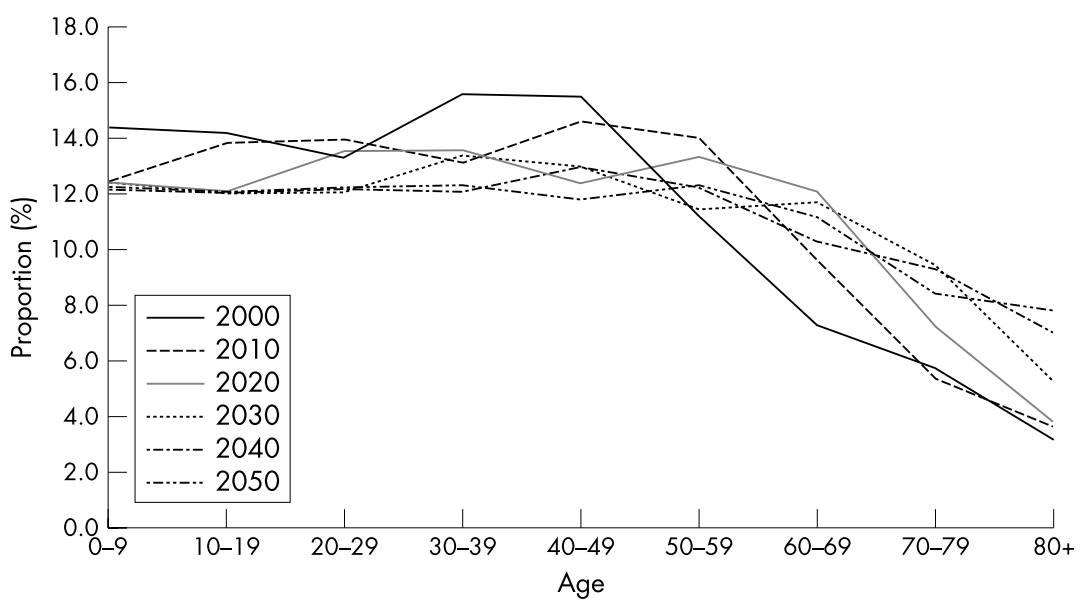

Figure 2 Population distribution by 10 year age group in Northern America from 2000 to 2050 . $^{2}$ condition. ${ }^{27}$ A recent bibliometric study showed that measured by literature citation, musculoskeletal diseases ranked ninth among 12 major Medline disease categories in 1991 and 1996. ${ }^{28}$ Authors concluded that arthritis and rheumatism are neglected health priorities, receiving far less attention in the scientific literature than is warranted by their burden. These deductions emerge despite the fact that several attempts have been made to highlight arthritis as an extending public health problem in a demographic transition era since the early nineties. ${ }^{1029-32}$

In line with demographic changes and in view of the poor awareness of the burden of arthritis, the United Nations, the World Health Organisation, and national governments have launched, concomitantly with health professionals and patient organisations, the "Bone and Joint Decade" for the years 2000-2010. ${ }^{33}{ }^{34}$ This large worldwide campaign aims at improving the health related quality of life for people with musculoskeletal conditions by giving patients knowledge and information and by advancing research on prevention, diagnosis, and treatments.

There is growing evidence that we are now better armed to reduce the impact of arthritis. Risk factors for arthritis, other than age and sex, have been identified. ${ }^{45}$ Modifying the risk factors may have direct preventive applications. $^{35-37}$ As an example, interventions such as weight control, ${ }^{38}{ }^{39}$ promotion of physical activity, and behavioural changes ${ }^{39-44}$ have been shown to slow the progression of arthritis. In addition, early diagnosis ${ }^{45}{ }^{46}$ and appropriate therapeutic management ${ }^{47} 48$ may help to improve the quality of life of arthritic patients. As a last resort, joint arthroplasties are available to relieve pain and return patients to better physical function. ${ }^{49}{ }^{50}$ Recent reports emphasised the underuse of hip and knee arthroplasties $^{51}$ and misperception about the nature of arthritis which may prevent arthroplasty being carried out. ${ }^{52}$

It is important to change current opinion on arthritis and to increase knowledge of the possibilities available at each level (prevention, therapeutics, and education) for controlling symptoms, postponing disability, and giving patients the ability to cope daily with the disease. A lack of awareness about effective interventions for arthritis might have prevented both patients and health professionals from implementing effective intervention. ${ }^{25}$ Economic considerations and health insurance policies cannot be ignored, and health professionals should continue in their efforts to identify and support cost effective actions. 
Ann Rheum Dis 2004;63:1-3.

doi: 10.1136/ard.2003.009613

\section{Authors' affiliations}

O Ethgen, WHO Collaborating Centre for

Public Health Aspects of Osteoarticular

Disorders; Department of Public Health

Sciences, University of Liège-CHU Sart

Tilman, Avenue de l'Hôpital 3, B 23, 4000

Liège Belgium

J-Y Reginster, WHO Collaborating Centre for Public Health Aspects of Osteoarticular Disorders; Department of Public Health Sciences, University of Liège-CHU Sart Tilman, Avenue de l'Hôpital 3, B 23, 4000 Liège Belgium; Bone and Cartilage Research Unit, University of Liège-CHU Centre Ville, Quai G Kurth 45 - B K1, 4020 Liège Belgium

Correspondence to: $\mathrm{MrO}$ Ethgen, University of Liege, Sante Publique CHU Sart Tilman, B23, 4000 Liege, Belgium; o.ethgen@ulg.ac.be

\section{REFERENCES}

1 Population Division of the Department of Economic and Social Affairs of the United Nations. World population prospects: the 2000 revision. New York: United Nations, 2001

2 Population Division of the Department of Economic and Social Affairs of the United Nations. World population prospects: the 2000 revision and world urbanization prospects: the 2001 revision. http://esa.un.org/unpp/.

3 Kalache A. Active aging makes the difference [editorial]. Bull World Health Org 1999;77:299.

4 Kelsey JL, Hochberg MC. Epidemiology of chronic musculoskeletal disorders. Ann Rev Public Health 1988;9:379-401.

5 Reginster JY. The prevalence and burden of arthritis. Rheumatology (Oxford) 2002;41(suppl 1):3-6.

6 Hughes SL, Dunlop D. The prevalence and impact of arthritis in older persons. Arthritis Care Res 1995:8:257-64.

7 Guralnik JM, Kaplan GA. Predictors of healthy aging: prospective evidence from the Alameda County Study. Am J Public Health 1989;79:703-8.

8 Kosorok MR, Omenn GS, Diehr P, Koepsell TD Patrick DL. Restricted activity days among older adults. Am J Public Health 1992;82:1263-7.

9 Ettinger WH, Fried LP, Harris T, Shemanski L, Schulz R, Robbins J, for the CHS Collaborative Research Group. Self-report causes of physical disability in older people. The Cardiovascular Health Study. J Am Geriatr Soc 1994:42:1035-44.

10 Badley EM. Population projections and the effect on rheumatology. Ann Rheum Dis 1991;50:3-6.

11 Zola IK. Aging, disability and the home-care revolution. Arch Phys Med Rehabil 1990;71:93-6.

12 Jones DA, Vetter NJ. A survey of those who care for the elderly at home; their problems and needs. Soc Sci Med 1984:19.511-14.

13 Mizuno E, Hosak T, Ogihara R, Hogano H, Mano $Y$. Effectiveness af a stress management program for family caregivers of the elderly at home. J Med Dental Sci 1999:46: 145-53.

14 Wolfe F, Hawley DJ. The longterm outcomes of rheumatoid arthritis: work disability: a prospective 18 years study of 823 patients. J Rheumatol 1998;25:2108-17.
15 Yelin EH. Musculoskeletal conditions and employment. Arthritis Care Res 1995;8:311-19.

16 Badley EM, Wang PP. The contribution of arthritis and arthritis disability to nonparticipation in the labor force: a Canadian example. J Rheumatol 2001 ;28:1077-82.

17 Yelin E, Lubeck D, Holman H, Epstein W. The impact of rheumatoid arthritis and osteoarthritis: the activities of patients with rheumatoid arthritis and osteoarthritis compared to controls. J Rheumatol 1987;14:710-17.

18 De Bock GH, Kaptein AA, Touw-Otten F, Mulder JD. Health-related quality of life in patients with osteoarthritis in a family practice setting. Arthritis Care Res 1995;8:88-93.

19 Wolfe F, Hawley DJ. The relationship between clinical activity and depression in rheumatoid arthritis. J Rheumatol 1993;20:2032-7.

20 Dexter P, Brandt K. Distribution and predictors of depressive symptoms in osteoarthritis. J Rheumato 1994:21:279-86.

21 Lanes SF, Lanza LL, Radensky PW, Yood RA Meenan RF, Walker AM, et al. Resource utilization and cost of care for rheumatoid arthritis and osteoarthritis in a managed care setting: the importance of drug and surgery costs. Arthritis Rheum 1997;40:1475-81.

22 Gabriel SE, Crowson CS, Campion ME, O'Fallon WM. Direct medical costs unique to people with arthritis. J Rheumatol 1997;24:719-25.

23 Dunlop DD, Manheim LM, Yelin EH, Song J, Chang RW. The costs of arthritis. Arthritis Rheum 2003:49:101-13

24 Price JH, Hillman KS, Toral ME, Newell S. The public's perceptions and misperceptions of arthritis. Arthritis Rheum 1983:26:1023-7.

25 Rao JK, Callahan LF, Helmick CG. Characteristics of persons with self-reported arthritis and other rheumatic conditions who do not see a doctor J Rheumatol 1997;24:169-73.

26 Woolf AD, Akesson K. Understanding the burden of musculoskeltal conditions. The burden is huge and not reflected in national health priorities. $B M$ 2001;322:1079-80.

27 Croos CP. Anderson GF, Powe NR. The relation between funding by the National Institute of Health and the burden of disease. N Engl J Med 1999;340:1881-7.

28 Glazier RD, Fry J, Badley E. Arthritis and rheumatism are neglected health priorities: bibliometric study. J Rheumato $2001 ; 28: 706-11$

29 Badley EM, Crotty M. An international comparison of the estimated effect of the aging of the population on the major cause of disablement musculoskeletal disorders. J Rheumatol 1995;22:1934-40.

30 Badley EM, Wang PP. Arthritis and the aging population: projections of arthritis prevalence in Canada 1991 to 2031. J Rheumatol 1998;25:138-44.

31 Helmick CG, Lawrence RC, Pollard RA, Lloyd E, Heyse SP. Arthritis and other rheumatic conditions: who is affected now, who will affected later? Arthritis Care Res 1995;8:201-11.

32 Birrel F, Johnell O, Silman A. Projecting the need for hip replacement over the next three decades: influences of changing demography and threshold for surgery. Ann Rheum Dis 1999;58:569-72.

33 Harris ED. The Bone and Joint Decade: a catalys for progress. Arthritis Rheum 2001:44:1969-70.

34 The Bone and Joint Decade. Joint motion 20002010. http://www. bonejointdecade.org

35 Felson DT, Zhang $Y$. An update on the epidemiology of knee and hip osteoarthritis with a view to prevention. Arthritis Rheum 1998;41:1343-55.

36 Hubert HB, Bloch DA, Oehlert JW, Fries JF. Lifestyle habits and compression of morbidity.
J Gerontol A Biol Sci Med Sci 2002;57:M347-51

37 Morley JE, Flaherty JH. It's never too late: health promotion and illness prevention in older persons. $\checkmark$ Gerontol A Biol Sci Med Sci 2002;57:M338-42.

38 Felson DT, Zhang Y, Anthony JM, Naimark A, Anderson JJ. Weight loss reduces the risk for symptomatic knee osteoarthritis in women. The Framingham Study. Ann Intern Med 1992;116:535-9.

39 Sturmer T, Gunther KP, Brenner H. Obesity, overweight and patterns of osteoarthritis: the Ulm Osteoarthritis Study. J Clin Epidemiol 2000;53:307-13

40 Lorig KR, Mazonson PD, Holman HR. Evidence suggesting that health education for selfmanagement in patients with chronic arthritis has sustained health benefits while reducing health care cost. Arthritis Rheum 1993;36:439-46.

41 Kovar PA, Allegrante JP, MacKenzie CR, Peterson MGE, Gutin B, Charleson ME. Supervised fitness walking in patients with osteoarthritis of the knee. Ann Intern Med 1992; 1 16:529-34.

42 Calfas KJ, Kaplan RM, Ingram RE. One-year evaluation of cognitive-behavioral intervention in osteoarthritis. Arthritis Care Res 1992;5:202-9.

43 Sharpe I, Sensky T, Timberlake N, Ryan B, Allard $Q$. Long-term efficacy of a cognitive behavioural treatment from a randomized controlled trial for patients recently diagnosed with rheumatoid arthritis. Rheumatology (Oxford) 2003:42:435-41

44 Macera CA, Hootman JM, Sniezek JE. Major public health benefits of physical activity. Arthritis Rheum 2003;49:122-8.

45 Wiles NJ, Lunt $M$, Barrett EM, Bukhari $M$ Silman AJ, Symmons DP, et al. Reduced disability at five years with early treatment of inflammatory polyarthritis. Results from a large observational cohort, using propensity models to adjust for disease severity. Arthritis Rheum 2001;44:1033-42.

46 Liang MH, Fortin P. Management of osteoarthritis of the hip and knee. N Engl J Med 1991;325:125-7.

47 Ehrich EW, Bolognese JA, Watson DJ, Kong SX Effect of rofecoxib therapy on measures of healthrelated quality of life in patients with osteoarthritis. Am J Manage Care 2001;7:609-16.

48 Reginster JY, Deroisy R, Rovati LC, Lee RL, Lejeune $E$, Bruyere $O$, et al. Long-term effects of glucosamine sulphate on osteoarthritis progression: a randomised, placebo-controlled clinical trial. Lancet 2001;357:251-6.

49 Fortin PR, Clarke AE, Joseph L, Liang MH, Tanzer M, Ferland D, et al. Outcomes of total hip and knee replacement. Preoperative functional status predicts outcomes at six months after surgery. Arthritis Rheum 1999:42:1722-8

50 Bachmeier CJM, March LM, Cross MJ, Lapsley HM, Tribe KL, Courtenay BG, et al. A comparison of outcomes in osteoarthritis patients undergoing total hip and knee replacement surgery. Osteoarthritis Cartilage 2001;9:137-46.

51 Hawker GA, Wright JG, Coyte PC, Williams J Harvey B, Glazier R, et al. Differences between men and women in the rate of use of the hip and knee arthroplasty. N Engl J Med 2000;342:1016-22

52 Hudak PL, Clark JP, Hawker GA, Coyłe PC Mahomed NN, Kreder HJ, et al. "You're perfect for the procedure! Why don't you want it?" Elderly arthritis patients' unwillingness to consider total joint arthropasty surgery: a qualitative study Med Decis Making 2002;22:272-8. 